УДК 621.039.5; 621.438

\title{
ВОЗМОЖНОСТИ ПОВЫШЕНИЯ ЭФФЕКТИВНОСТИ ВОЗДУШНОЙ УТИЛИЗАЦИИ ТЕПЛОТЫ ЗА ГАЗОТУРБИННЫМИ ПРИВОДАМИ
}

\begin{abstract}
Халатов А.А., академик НАН Украины, Коваленко А.С., канд. техн. наук, Северин С.Д., канд. техн. наук, Коваленко Г.В., канд. техн. наук

Институт технической теплофизики НАН Украины, ул. Желябова, 2а, Киев, 03680, Украина

Виконано аналіз трьох способів підвищення ефективності ВТТУ за привідною ГТУ. Представлено порівняння ефектів перерозширення повітря на виході з ВТТУ, зволоження повітря перед турбіною ВТТУ і збільшення ККД повітряної турбіни.

Выполнен анализ трех способов повышения эффективности ВТТУ за приводной ГТУ. Представлено сравнение эффектов перерасширения воздуха на выходе из ВТТУ, увлажнения воздуха перед турбиной ВТТУ и увеличения КПД воздушной турбины.

The analysis of three ways of increasing the efficiency of the air heat recovery turbine unit (AHRTU) behind the mechanical drive gas turbine unit is performed. A comparison of the effects of the air overexpansion at the AHRTU outlet, air humidification in front of the turbine of AHRTU and increase in the efficiency of the air turbine is given.
\end{abstract}

Библ. 11, рис. 6.

Ключевые слова: газотурбинный привод, выходящие газы, утилизация теплоты, теплоноситель, энергетический КПД.

\section{Обозначения:}

$c$ - скорость;

$c_{p}-$ удельная теплоемкость при постоянном давлении;

$d=G_{\text {пара }} / G_{\text {вр }}-$ относительная доля пара;

$i$ - энтальпия;

$G$-расход;

$K_{p}$ - параметр перерасширения рабочего тела в выходном патрубке;

$L$ - работа;

$N$-мощность;

$p$-давление;

$q_{1}$ - теплота, подводимая в термодинамическом процессе к 1 кг рабочего тела;

$s$ - энтропия;

$T$ - температура рабочего тела;

$\eta$ - коэффициент полезного действия;

$\overline{\eta_{э y}}=\eta_{\text {эу }} / \eta_{\text {эур }}$ - относительный энергетический КПД комбинированной установки;

$\sigma_{\text {рег }}-$ степень регенерации;

г-гечение перед турбиной;

c - сечение на выходе из выходного сопла (патрубка);

т - сечение за силовой турбиной;

тк - сечение за турбиной компрессора.

\section{Верхние индексы:}

•- заторможенный поток.

Нижние индексы:

в - воздух;

вст -воздушная силовая турбина;

втту - воздушная теплоутилизирующая турбинная

установка;

г- газ; сечение перед турбиной;

гтд - газотурбинный двигатель;

к - сечение за компрессором;

н -невозмущенный поток;

п - пар;

пр - привод;

p- расчетный;

c - сечение на выходе из выходного сопла (патрубка;

т - сечение за турбиной;

тк - сечение за турбиной комрессора;

у - установка;

э- энергетический.

\section{Сокращения:}

ВТТУ - воздушная теплоутилизирующая турбинная установка;

ГПА - газоперекачивающий агрегат; 
ГТД - газотурбинный двигатель;

ГТП - газотурбинный привод;

ГТС - газотранспортная система;

ГТУ - газотурбинная установка;

КИТ - коэффициент использования теплоты;

\section{Введение}

В украинской газотранспортной сети (ГТС) основным силовым элементом газотурбинного привода (ГТП) газоперекачивающего агрегата (ГПА) на компрессорных станциях (КС) служит газотурбинный двигатель (ГТД). В качестве топлива для его работы применяется природный газ, транспортируемый по магистрали. Снижение расхода этого топлива, которое обычно оценивается энергетическим коэффициентом полезного действия (КПД), остается весьма актуальной проблемой. Подробное обоснование необходимости улучшения экономичности ГТД, эксплуатируемого в составе ГПА, было рассмотрено ранее $[1,2]$.

В то же время из практики газотурбостроения хорошо известны способы, позволяющие исполь-
КПД - коэффициент полезного действия;

КС - компрессорная станция;

КУ - комбинированная установка;

ТА - теплообменный аппарат;

ТБК - турбокомпрессор.

зовать тепловую энергию потока после совершения им механической работы и, тем самым, уменьшить безвозвратные потери теплоты. С точки зрения последующего применения этой энергии различают два направления: регенерацию и утилизацию теплоты. Данные ГТД, эксплуатируемых украинской ГТС в качестве приводов [3], показывают, что регенерация теплоты выходящих газов перестала применяться уже с 80-х годов прошлого века (рис. 1). Это связано с опережающим ростом температуры воздуха после компрессора (из-за роста степени повышения давления) по отношению к температуре продуктов сгорания за силовой турбиной ГТД. На практике такая ситуация привела к исчезновению потенциала теплоты, необходимого для организации процесса регенерации.

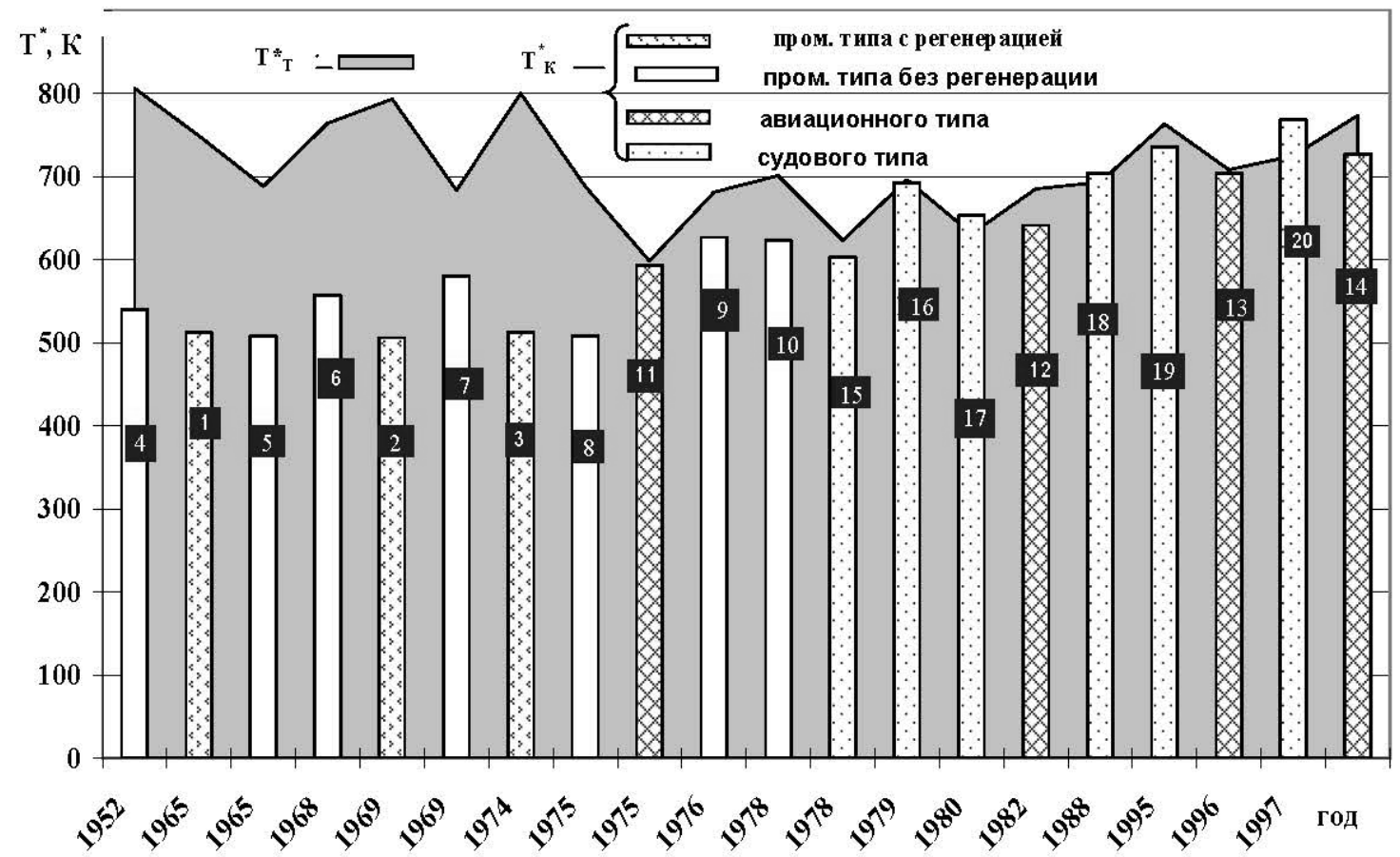

Рис. 1. Зависимость температуры потока за компрессором и турбиной привода ГТД от типа привода и начала его серийного производства:

1 - 3 и 4-10 - промышленного типа соответственно с регенерацией (ГТ-750-6; ГТК-10, ГТНР-10) и без нее (МS3002, ГТД-6-750, МS5002, Центавр-3002, ГТН-6, ГТН-16, ГПА25/76);

11 - 14 - конвертируемый, авиационного типа (НК-12СТ, НК-16СТ, Д-336-2, Д336-1-8); 15-20 - конвертируемый, судового типа (ДР-59Л, ДТ-71П, ДЖ-59Л, ДГ-90, ДН-80Л, ДН-70). 
Поэтому в настоящее время актуальным становится поиск возможностей утилизации выбросной тепловой энергии в устройстве, не связанном с термодинамическим циклом приводного двигателя, что, естественно, предполагает использование дополнительного рабочего тела (вода, низкокипящее рабочее тело, воздух). В зависимости от необходимости в таком устройстве может быть реализован теплосиловой, теплофикационный или холодильный цикл.

Анализ особенностей функционирования проектируемых, опытных или серийных образцов комбинированных установок (КУ) на базе ГТД, объединяющих оба термодинамических цикла в единый, бинарный цикл [4 - 9], свидетельствует о практической возможности и целесообразности применения воздушного теплосилового цикла для утилизации теплоты выходящих из ГТД газов.

Ранее авторами были представлены результаты расчетного исследования рабочего процесса воздушной теплоутилизирующей турбинной установки (ВТТУ), работающей в комбинации с основным ГТД [1]. При этом подвод теплоты к рабочему телу (воздуху) в цикле ВТТУ производился в теплообменном аппарате (ТА), установленном за приводной турбиной ГПА. Была определена степень влияния расхода воздуха и его температуры после теплообменного аппарата (ТА) на основные данные ВТТУ (мощность и энергетический КПД) в условиях полного расширения воздуха в ней и неизменном гидравлическом сопротивлении воздушного тракта.

В то же время представляется необходимым исследовать возможность расширения утилизационных возможностей ВТТУ рассматриваемой схемы и, следовательно, реальность улучшения за счет этого экономичности всей КУ. Обычно в теплосиловых установках такого типа различают два энергетических КПД [10]. Один из них, КПД привода, оценивает степень преобразования тепла, полученного при сгорании топлива, в механическую работу на фланце выходного вала привода. Другой, энергетический КПД установки, дополнительно учитывает механическую работу теплоутилизирующих устройств:

$\eta_{\text {эу }}=\left(N_{\text {гтд }}+N_{\text {втту }}\right) / q_{1}$,

где

$N_{\text {втту }}=G_{\text {в }} \cdot L_{\text {вст }}=G_{\text {в }} \cdot c_{\text {рв }} \cdot T_{\text {в тк }}^{*}\left[1-\left(\mathrm{p}_{\mathrm{H}} / \mathrm{p}^{*}{ }_{\text {в тк }}\right)^{0,285}\right] \cdot \eta^{*}{ }_{\text {вст }}^{*}$
В случае использования для утилизации тепловой энергии теплофикационного или холодильного циклов, для оценки экономичности всей установки применяется коэффициент использования теплоты (КИТ) [10]. Последний учитывает дополнительный эффект преобразования полученной в цикле ГТД и выбрасываемой теплоты в другие виды энергии, т.е. ее утилизацию.

Таким образом, ясно, что рост эффекта утилизации теплоты в установке рассматриваемой конфигурации возможен лишь в случае роста мощности воздушной силовой турбины. В свете вышеизложенного в настоящей работе предложено исследовать влияние на работу силовой турбины ВТТУ, которая является источником дополнительной полезной механической энергии, ряда факторов. Сюда относятся: КПД силовой турбины, степень перерасширения рабочего тела в ней и подача водяного пара в поток перед турбиной турбокомпрессора ВТТУ. Для последнего случая в качестве одного из вариантов предложено базовую схему ВТТУ [1] модернизировать путем установки дополнительной системы подготовки пара перед подачей его в воздушный поток после ТА (рис. 2).

Не вдаваясь в вопросы конструктивного исполнения в КУ предлагаемых мероприятий, предлагается проанализировать результаты расчетного исследования влияния каждого из обозначенных факторов на степень изменения ее энергетического КПД.

Расчетные зависимости представлены в относительных координатах. За базовый уровень принят расчетный режим работы КУ $\left(\eta_{\text {эур }}=\right.$ $=38 \%$ ), полученный на начальном этапе исследования установки в составе ГТД судового типа ДН-80Л $\left(N_{\text {гтд }}=25\right.$ МВт; $G_{г}=87,5$ кг $/ \mathrm{c} ; \sigma_{\text {рег }}=0,85$; $\left.T_{\text {т }}^{*}=750 \mathrm{~K}\right)$ и рассматриваемой ВТТУ $\left(G_{\mathrm{B}}=\right.$ $\left.=65 \mathrm{\kappa г} / \mathrm{c} ; \eta_{\text {встр }}^{*}=0,80\right)[1]$.

\section{Гидравлическое совершенство силовой воздушной турбины}

Анализ характера изменения энергетического КПД установки в исследованном диапазоне уровня гидравлических потерь в воздушной силовой турбине (рис. 3) показывает монотонное его возрастание с увеличением расхода воздуха через ВТТУ, которое по мере роста расхода воз- 
духа становится менее интенсивным. Кроме того, темп этого возрастания становится более заметным по мере гидравлического совершенствования проточной части силовой турбины ВТТУ.

Так, с увеличением ее КПД с 0,80 до 0,85 , т.е. на 6,25 \%, энергетический КПД всей КУ при расчетном значении расхода воздуха работы ВТТУ возрастает на $0,35 \%$.
При увеличении же КПД силовой турбины от 0,80 до 0,90 , т.е. на $12,5 \%$, эффективность использования топлива в КУ, по сравнению с предыдущим случаем, возрастет в два раза (на $0,7 \%$. Исследованный диапазон изменения КПД силовой воздушной турбины позволяет определить характер его влияния на экономичность КУ в процессе эксплуатации.

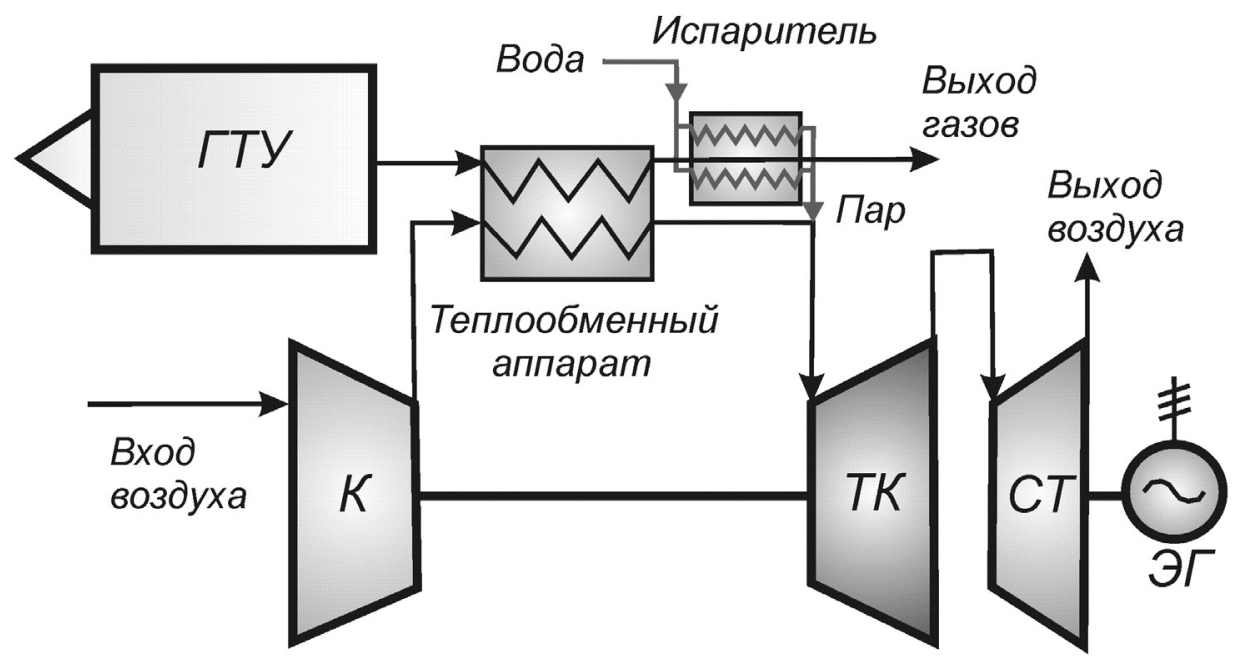

Рис. 2. Схема энергетической установки с ВТТУ и увлажнением воздуха перед турбиной компрессора: ГТУ-газотурбинная установка; К-компрессор; ТК- турбина компрессора;

СТ-силовая турбина; ЭГ-электрогенератор.

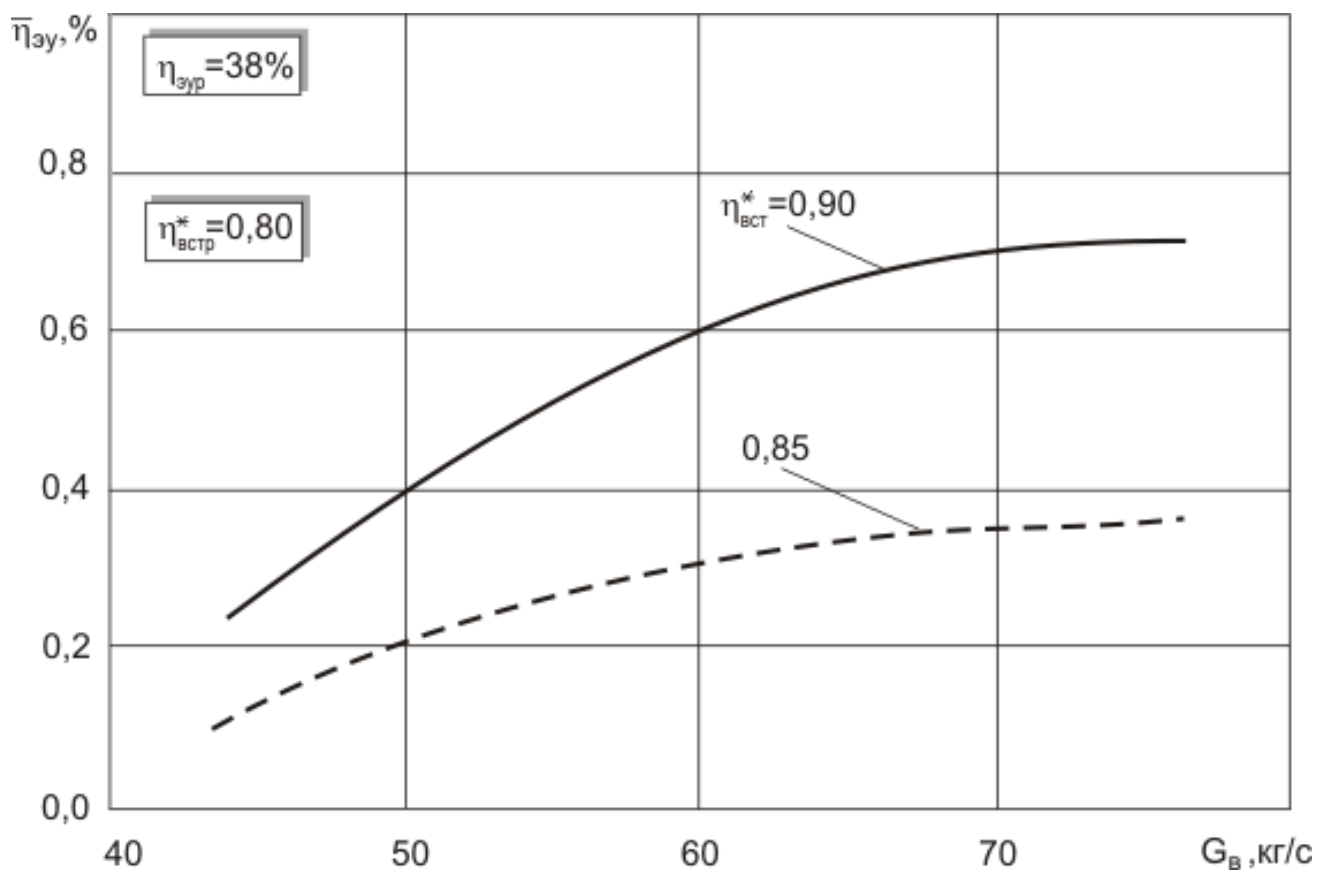

Рис. 3. Зависимость энергетического КПД комбинированной установки от КПД силовой турбины ВТТУ и расхода воздуха через нее. 


\section{Перерасширение газа в свободной турбине}

Теоретическое обоснование возможности увеличения работы турбины за счет расширения рабочего тела в ней до давления ниже атмосферного (т.н. перерасширение потока) давно известно. В этом случае при неизменных параметрах потока на входе в турбину его температура и статическое давление на выходе падают, а скорость увеличивается. Последующий выброс рабочего тела в атмосферу обеспечивается установкой диффузорного выпускного патрубка. На тепловой диаграмме это выглядит как увеличение работы приводной воздушной турбины и снижение кинетической энергии потока на выходе из диффузора (рис. 4).

На практике такой метод применяется в различных областях промышленности и на воздушном транспорте, с различными, в зависимости от области использования, ограничениями.

Так, например, в авиационных ГТД значительное снижение давления на выходе из турбины приводит к уменьшению плотности рабочего тела в этом сечении, увеличению длины лопаток последней ступени турбины и угла меридионального раскрытия ее проточной части. Это затрудняет обеспечение прочности и достижение высокого КПД турбины [11]. Расчеты показывают (рис. 5), что увеличение перерасширения воздуха на силовой турбине ВТТУ (уменьшение парамет-

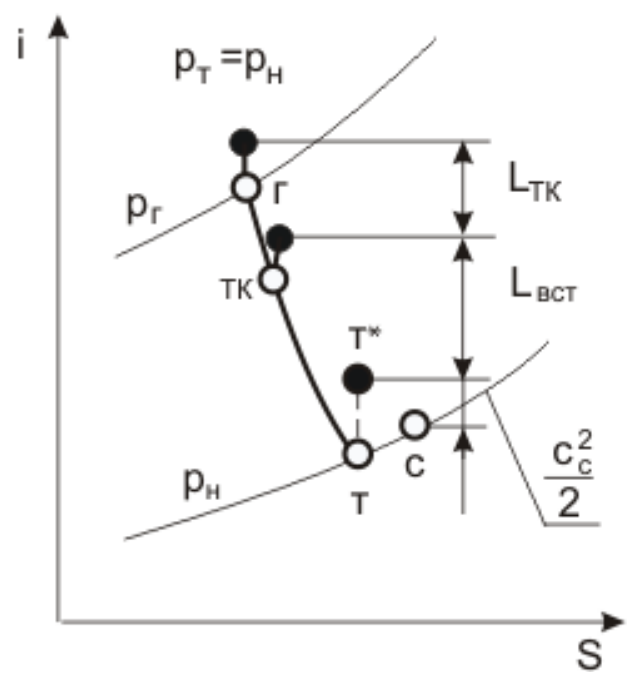

ра перерасширения $K_{\mathrm{p}}$ ) повышает экономичность КУ при любом его расходе.

При этом, с возрастанием расхода воздуха такое улучшение экономичности КУ выглядит все более существенно. Так увеличение расхода воздуха через воздушную силовую турбину с 50 кг/с до 70 кг/с при минимальном перерасширении $\left(K_{\mathrm{p}}=0,99\right)$ вызывает рост относительного энергетического КПД установки на $15 \%$, а при максимальном $\left(K_{\mathrm{p}}=0,97\right)$ на $25 \%$.

На расчетном режиме работы ВТТУ $\left(G_{\text {в }}=\right.$ $=65$ кг/с) относительное увеличение энергетического КПД установки составляет от $0,35 \%$, при минимальном перерасширении, до 1,05\% - при максимальном.

Основной причиной роста энергетического КПД установки при уменьшении значения $K_{\mathrm{p}}$ является увеличение работы силовой турбины ВТТУ из-за повышения срабатываемого на ней теплоперепада.

\section{Увлажннение воздуха на входе в турбину ВТТУ}

Рассмотренные выше методы повышения экономичности КУ рассматривали возможности решения этой проблемы только с точки зрения совершенствования рабочего процесса ВТТУ. Однако, если проанализировать совместную работу ГТД и ВТТУ, то можно найти и другие способы экономии топливного газа. Одним из них

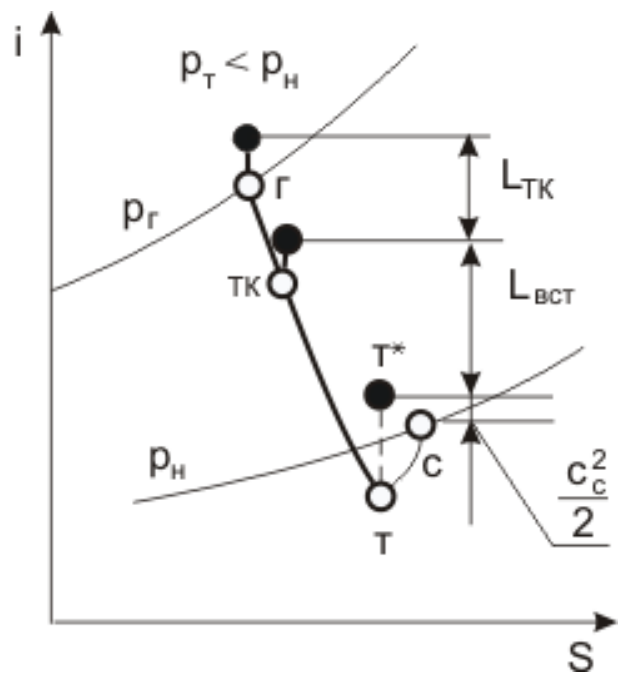

Рис. 4. Влияние степени расширения рабочего тела в силовой турбине ВТТУ на ее работу: a-полное расширение $\left(p_{\mathrm{T}}=p_{\mathrm{H}}\right) ; \sigma$-перерасширение $\left(p_{\mathrm{T}}<p_{\mathrm{H}}\right)$ 
является дополнительная утилизация теплоты выходящих газов ГТД с помощью пара, генерируемого в испарителе, размещаемом за приводной турбиной ГТД. Этому способствуют исключительно благоприятные для отбора теплоты теплофизические характеристики воды и пара, а также наличие фазового перехода между ними.

Получаемый пар используется для увлажнения воздуха, поступающего на вход турбины компрессора ВТТУ, или же силовой воздушной турбины. Мощность последней, согласно выражению (2), в любом случае будет увеличиваться как за счет дополнительной массы подводимого пара, так и за счет большей теплоемкости (для расчетного режима примерно в 1,9 раза) по сравнению с сухим воздухом. Однако это имеет место только при равенстве температуры пара температуре воздуха на входе в силовую турбину или ее превышении. Подмешивание же более холодного, чем воздух, пара (при прочих равных условиях) снижает позитивный вклад в экономию топлива удельной теплоемкости пара и дополнительного подвода его массы.

Следует учитывать, что дополнительная подача пара в обоих случаях приводит к изменению баланса мощностей компрессора ВТТУ и его турбины и соответствующему изменению мощности воздушной силовой турбины, по сравнению с базовым режимом. Происходит перераспределение работ между турбиной компрессора и воздушной силовой турбиной в сторону увеличения работы последней. В итоге возникает необходимость перепроектирования одной или обеих турбин ВТТУ.

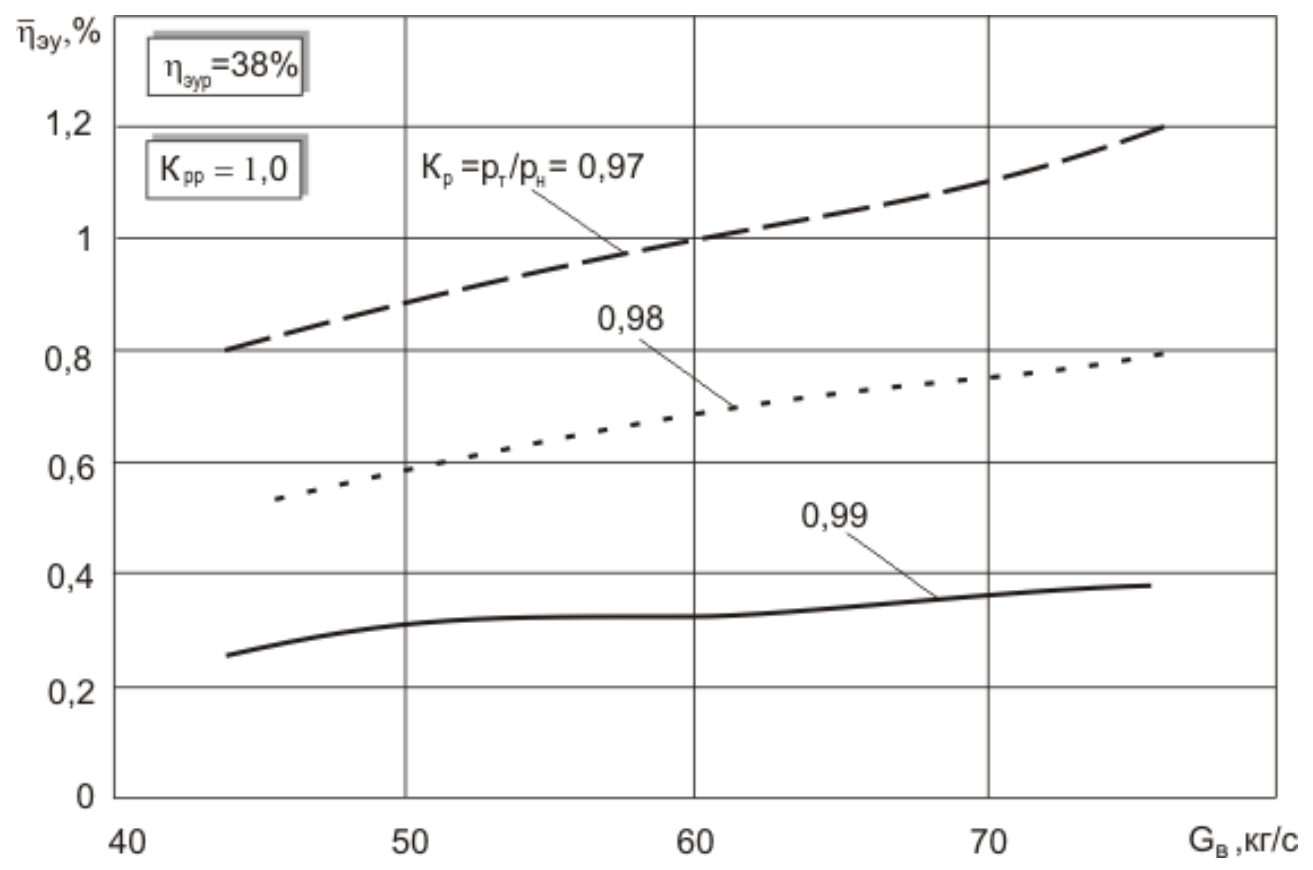

Рис. 5. Влияние степени перерасиирения воздуха в силовой турбине ВТТУ и расхода воздуха через нее на энергетический КПД комбинированной установки.

Результаты исследования при подаче пара на вход турбины компрессора и неизменной температуре пара свидетельствуют об ощутимом влиянии влагосодержания воздуха на экономичность КУ (рис. 6).

Характер протекания расчетных зависимостей энергетического КПД КУ по расходу воздуха через ВТТУ пологий. При небольшой влаж- ности $(d=0,02)$ и расходе воздуха в пределах $50 \ldots 70$ кг/с КПД улучшается на $2 \ldots 3,5 \%$, в зависимости от расхода воздуха. Увеличение влагосодержания (до $d=0,08$ ) существенно (на $11 \ldots 16 \%$ ) способствует увеличению экономичности КУ.

Применение увлажнения воздуха улучшает экономичность КУ во всем диапазоне расхо- 
дов воздуха через ВТТУ. Однако с увеличением последнего этот эффект с ростом увлажнения воздуха несколько снижается. Так при изменении расхода воздуха от 50 кг/с до 70 кг/с темп роста энергетического КПД снизился с 1,75 для $d=0,02$ до 1,45 для $d=0,08$.

На расчетном режиме $\left(G_{\text {в }}=65\right.$ кг/с) рост энергетического КПД составляет от 3 \% для влажности $d=0,02$ до $15 \%$ при влагосодержании $d=0,08$.

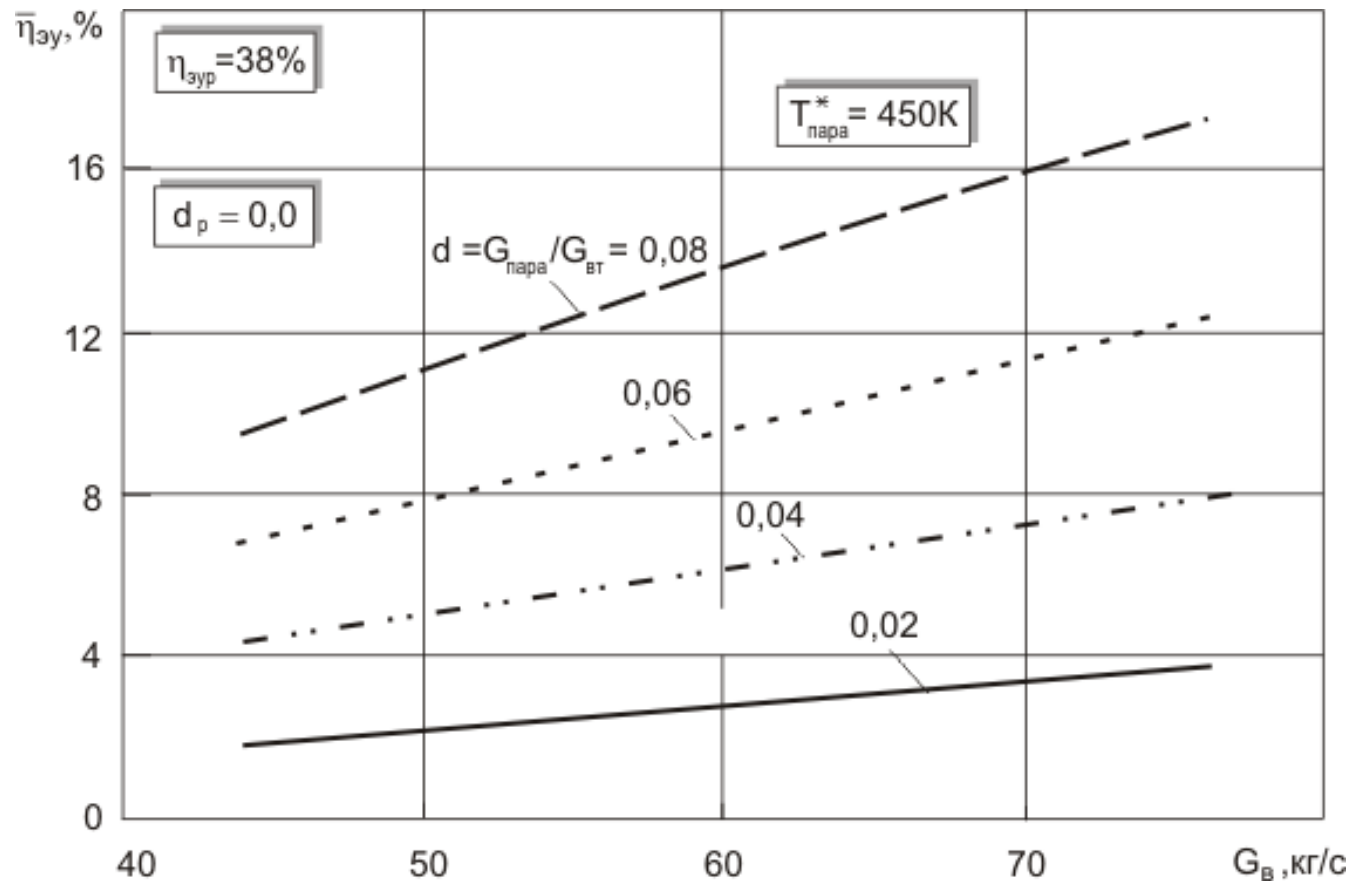

Рис. 5. Влияние степени перерасширения воздуха в силовой турбине ВТТУ и расхода воздуха через нее на энергетический КПД комбинированной установки.

\section{Выводы}

Анализ потенциальных возможностей повышения экономичности комбинированной установки на базе серийного привода ДН-80Л украинской газотранспортной сети и воздушной теплоутилизирующей турбинной установки показал:

1. Возможности повышения экономичности современных газотурбинных приводов украинской газотранспортной сети с помощью регенерации теплоты выходящих газов исчерпаны.

2. Перспективным направлением снижения удельного расхода топлива является утилизация теплоты выбрасываемых газов в комбинированных установках на базе газотурбинного привода и ВТТУ.

3. Снижение гидравлических потерь в силовой турбине ВТТУ незначительно влияет на экономичность комбинированной установки. Так с ростом КПД воздушной силовой турбины от
$80 \%$ до 90 \% расчетный энергетической КПД установки увеличивается всего на $0,7 \%$.

4. Для воздушной силовой турбины с перерасширением рабочего тела при снижении давления на выходе из нее на $3 \%$, по сравнению с атмосферным давлением, в выбранной расчётной точке эффект увеличения экономичности комбинированной установки составляет около $1 \%$;

5. При подаче пара с температурой 450 К на вход турбины ВТТУ рост мощности ее силовой турбины составляет от $3 \%$ (при $d=0,02)$ до $14 \ldots 15 \%$ (при $d=0,08)$. Однако это связано с организацией сложного цикла утилизации влаги на выходе из ВТТУ;

6. Установлено, что наиболее эффективным способом повышения экономичности в комбинированных установках на базе газотурбинного привода и ВТТУ является увлажнение воздуха на входе в воздушную турбину. 


\section{ЛИТЕРАТУРА}

1. Халатов А.А., Северин С.Д., Коваленко А.С., Бурлака В.В. Анализ воздушного цикла утилизации теплоты горячих газов за газотурбинными приводами ГТС Украины // Промышленная. теплотехника. - 2014. - Т. 6, №4. - С. 18 - 25.

2. Халатов А.А., Коваленко А.С. Перспективы снижения выбросов теплоты за газотурбинными приводами украинской газотранспортной системы // Промышленная. теплотехника. - 2015. - T. 37, №2. - С. 48 - 58 .

3. Методика визначення виробничотехнологічних витрат природного газу на його видобування, транспортування магістральними газопроводами та експлуатацію підземних сховищ. К.: 2008. Mpe.kmu.goy.ua/fuel/doccatalog/ document?id=134907.

4. Low Cost "Air Bottoming Cycle" for Gas Turbines. Gas Turbine World, vol,21, № 3, 1991, p.61

5. Пятничко В.А., Крушневич Т.К., Пятничко A.И. Утилизация низкопотенциального тепла для производства электроэнергии с использованием пентана в качестве рабочего тела // Экология и ресурсосбережение. - 2003. - №4. - С. 3-6.

6. Дикий Н.А., Пятничко А.И., Карп И.Н. Производство электрической энергии по газопа- ровому циклу на комбинированном угольном и газовом топливе // Экология и ресурсосбережение. -2006 . - № 2. - С. 3 - 7.

7. Билека Б.Д. Комбинированные энергохолодильные установки для повышения эффективности работы газотранспортных систем // Промышленная теплотехника. - 2006. - Т. 28, № 2. - C. $132-138$.

8. Любчик Г.М., Реграги А., Литвинова Ю.Р., Репьях Ю.Р. Перспективы производства электрической и тепловой энергии на базе газотурбинных и комбинированных установок // Энергетика: экономика, технологии, экология. - 2008. - № 2. - C. $44-48$.

9. Romanov V.V., Chobenko V.N., Kuznetsov V.V., Movchan S.N., Kucherenko O.S, Shevtsov A.P. Performances and Application Perspectives of Air heat Recovery Turbine Units // Proceedings of ASME Turbo Expo 2010: Power for Land, Sea and Air, GT 2010, June 14 - 18, 2010, Glasgow,UK.

10. Курзон А.Г., Маслов Л.А. Судовые турбинные установки. - Л.: «Судостроение», 1991.$152 \mathrm{c}$.

11.Нечаев Ю.Н., Федоров Р.М. Теория авиационных двигателей. Ч.2. - М.: «Машиностроение», 1978.- 513 с. 


\section{POSSIBILITIES OF INCREASING THE EFFICIENCY OF AIR HEAT RECOVERY BEHIND OF GAS TURBINE DRIVES}

\section{Khalatov A.A., Kovalenko A.S., Severin S.D., Kovalenko .G.V.}

Institute of Engineering Thermophysics of the National Academy of Sciences of Ukraine, vul. Zhelyabova, 2a, Kiev, 03580,Ukraine.

Key words: gas turbine drive unit, exhaust gases, waste heat recovery, heat-transmitter, pover efficieney.

The analysis of statistical data of modern engines of gas turbine drives of the Ukrainian gas transmission network given in the paper has shown that the regeneration of heat of exhaust gases has exhausted its possibilities. The only way of reducing the thermal energy emitted to the atmosphere is only its recovery. The potential recovery of exhaust gases of the combined binary cycle plant consisting of the mass gas turbine engine and air heat recovery turbine plant have been analyzed in the paper. For this purpose the computational study of a number of factors affecting the energy efficiency of the combined plant has been done: the efficiency of the air power turbine, air overexpansion in it and its humidification. It has been found that the most effective way of reducing fuel gas consumption is humidification of the working air at the inlet to the air turbine.

References 11, figures 6.

1. Khalatov A.A., Severin S.D., Kovalenko A.S., Burlaka V.V. The analysis of air cycle of waste heat recovery after industrial gas turbines drive plants for Ukrainian gas transport system // Promyshlennaja teplotehnika. - 2014.- V.36, №4. - P. 18 - 25.

2. Khalatov A.A., Kovalenko A.S. Prospects of reducing emissions of heat bemind gas turbine drives ofukrainian gas transportation system// Promyshlennaja teplotehnika. - 2015.- V.37, № 2. P. $50-59$.

3. Procedure of determining production and technological costs of natural gas for its production transportation and operation of underground storage. - K.:2008.mpe.kmu.goy.ua/fuel/doccatalog/ document?id $=134907 \mathrm{~s}$.

4. Low Cost "Air Bottoming Cycle" for Gas Turbines. Gas Turbine World, V,21, № 3, 1991. $61 \mathrm{p}$.

5. Piatnichko V.A., Krushnevich T.K., Piatnichko A.I. Utilization of low-grade heat to produce electric power using pentane as working body //Ekologija I resursosbtrtzhenie. - 2003. - №4. - P. 3 - 6 .

6. Diky N.A., Piatnichko A.I., Karp I.N. Electric power production at gas-steam cycle on combined coal and gas fuel // Ekologija i resursozhberizhenie. -2006. - №2. - P. 3-7.

7. Bileka B.D. Combined power cooling plants for increasing to efficiency of operation of gas transport systems // Promyshlennaja teplotehnika. 2006.- V.28, №2. - P. 132 - 138.

8. Liubchik G.M., Regragi A., Litvinova Ju.R., Rep'jah Ju. R. Prospects of production of electric and thermal energy production on base of gas turbine and combined plants // Energetica: economika, tehnologii, ekologija. - 2008. - №8. - P. 44 - 48.

9. V.V.Romanov., V.N. Chobenko, V.V.Kuznetsov, S.N.Movchan, O.S. Kucherenko, A.P. Shevtsov. Performances and Application Perspectives of Air heat Recovery Turbine Units // Proceedings of ASME Turbo Expo 2010: Power for Land, Sea and Air, GT 2010, June 14 - 18, 2010, Glasgow,UK.

10. Kurzon A.G., Maslov L.A. Power turbine installations. - L.: "Sudostroenie", 1991. - 152 p.

11. Netschaev Ju.N., Fedorov R.M. Theory of aviation engines. P.2.- M.:"Mashinostroenie", 1978. $-513 \mathrm{p}$.

Получено 05.08.2015 Received 05.08.2015 